\title{
Physical Activity and Healing Through the Medicine Wheel
}

\author{
Lynn F. Lavallée
}

University of Toronto

digital.library.ryerson.ca/object/414

\section{Please Cite:}

Lavallée, L. F. (2007). Physical activity and healing through the medicine wheel. Pimatisiwin, 5(1), 127-153.

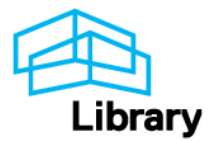




\title{
Physical Activity AND HeAling THROUGH THE MEDicine WHeEl
}

\author{
lynn F. Lavallée, PhD \\ UnIVERSITY OF TORONTO
}

Chi Miigwetch to the participants of this project who shared their knowledge and experiences.

Ah-hi to Elder Vern Harper for his wisdom. Miigwetch to Lee Maracle for editing parts of this paper.

This research was supported by the Wellesley Institute.

Lynn Lavallee is Métis (Algonquin/Cree/French). She is an Assistant Professor at Ryerson University. She can be reached at (416) 979-5000x4791 or lavallee@ryerson.ca. 


\section{INTRODUCTION}

According to Wesley-Esquimaux and Smolewski (2004), Indigenous people have experienced unremitting trauma as a result of colonization. The unremitting trauma of colonization included physical disconnection with children being removed from families and communities; mental disconnection with forced assimilation, forbidding the use of Aboriginal languages; changes in political and social structures; emotional disconnection by enforcement of the stereotypical view of "savage Indians" needing assimilation; and spiritual disconnection by banning of Indigenous cultural ceremonies (Chansonneuve, 2005).

Unremitting trauma has produced intergenerational "post-traumatic effects" demonstrated today in many Indigenous communities (WesleyEsquimaux and Smolewski, 2004). Evidence of post-traumatic effects manifests among Indigenous communities throughout the world. For example, globally, Indigenous people experience higher rates of illness and death compared with non-Indigenous people (World Health Organization, 2001). The generational impact of colonial trauma and forced assimilation has been termed historic trauma transmission (HTT) (Wesley-Esquimaux and Smolewski, 2004).

Historic trauma has removed many Indigenous people from their traditional values and beliefs. The maintenance of these values and beliefs is critical to good health. Although values and beliefs vary greatly across Indigenous nations there are many similarities; for example, many Aboriginal ${ }^{1}$ cultures approach health, wellness and healing through the "medicine wheel." In the medicine wheel balance between all four spheres of humanity is required: the mental, physical, emotional, and spiritual. This includes balance within ourselves, between other living things and Mother Earth (National Aboriginal Health Organization, 2005). An individual's health and wellness is based on maintaining balance between the emotional, physical, mental and spiritual realms. Healing from trauma and grief includes re-establishing a balance between these four realms (Anishnawbe Health Clinic, 2006).

The medicine wheel concept of health forms the theoretical basis for this research project. This study explores the impact of a physical activity program on one's life, identifying the interconnection to mental, emotional and

1 In this paper, the term Aboriginal is used when speaking about the Indigenous peoples of Canada. "This term includes Métis, Inuit and First Nations, regardless of where they live in Canada and regardless of whether they are 'registered' under the 'Indian Act' of Canada" (Archibald, 2006). 
spiritual well-being of urban Aboriginal adults. The physical activity program was martial arts offered at the Native Canadian Centre of Toronto (NCCT). This social, cultural, and spiritual program has been part of the NCCT since 1999. The instructor, George Lepine, is Cree and brings his Aboriginal teachings into the classroom. The martial arts taught include taekwondo and Oki Chi Taw. Lepine founded Oki Chi Taw, which is an Indigenous martial art and warrior system focusing on weaponry of the Plains Cree: tomahawk, gun stock war club, short lance, and long knife. Oki Chi Taw is recognized by the World Martial Arts Union as the official Indigenous martial art of Canada (NCCT, 2006). This martial arts program has seen many accomplishments including representation at the 6th, 7th, and 8th World Martial Arts Festival in South Korea; participation at the 2002 North American Indigenous Games (NAIG) where 11 of the 13 athletes won 17 medals; and participation at the 2005 Ontario Aboriginal Sport Circle Games.

Seventeen people from a variety of socio-economic and educational backgrounds participated in this project: ten males and seven females. They ranged in age from 26 to 49 with an average age of 34 . This research occurred in a Canadian urban centre in which many Nations or groups of Indigenous people live. Eleven participants, including myself, identified as Aboriginal (Ojibwe, Cree, and Métis) and one identified as Indigenous from South America. 1 will discuss my dual role as researcher and community member a little later.

There were six non-Aboriginal participants. The decision to include nonAboriginal people was made though discussion with the instructor of the program and Elder Vern Harper, the recognized Elder of the martial arts program. They felt that excluding those who were non-Aboriginal was inconsistent with the philosophy of the program and the NCCT. The NCCT and the martial art program welcome all people, Aboriginal and non-Aboriginal. Of the non-Aboriginal participants, one identified as hailing from Ecuador, one identified as being from Barbados, one identified as Greek, and two identified as "white.

The martial arts class involved testing individuals as they gained a certain level of expertise. With each successful test participants were awarded a new belt. The awarding of belts followed the principles of taekwondo. New participants are given a white belt which symbolizes the beginning of their journey. The progression of belt colours are from white to yellow stripe, yellow, green stripe, green, blue stripe, blue, red stripe, red, black stripe and then black. Once individuals achieve the level of a black belt, they continue into levels 
which are called dans. The first black belt level is called first dan, followed by second, third, fourth, etc. (G. Lepine, personal communication, April 2002). The 17 participants had a range of expertise as demonstrated by their belt levels. Five participants were white belts, seven participants were black belts and the remaining 5 ranged between blue and black stripe.

The impact of the program was explored using an Indigenous research framework and Indigenous research methods. Past research in the area of psychosocial sport development has focused on various constructs, such as biological or metabolic measures with little attention paid to psychological, social or cultural factors (Halas, 2001; Morris et al., 2003). Of the research that has focused on psychological, social, or cultural factors most has centred on self-esteem and has failed to look at the interconnectness of physical activity to other "domains" or "spheres" of one's life (Canadian Parks and Recreation Association, 1994; Coakley, 2002; Halas, 2001; Hartmann, 2003). An Indigenous research framework and the theoretical basis of this research, the medicine wheel, offer a different approach, focusing on the interconnectedness between the physical, mental, emotional, and spiritual and the interconnectedness of all living things.

This paper will provide details on the research framework and methods used to capture the participants' stories. Sharing circles and a method called Anishnaabe Symbol-Based Reflection will be explained. In addition, this paper will share the stories and symbols of the participants demonstrating the impact of physical activity on their emotional, mental and spiritual well-being. Finally, this paper will make recommendations for policy and future research.

\section{An Indigenous Research Framework}

An Indigenous research framework includes understanding the complex ways that the pursuit of knowledge and research are linked to imperial and colonial practices (Smith, 2002; Ten-Fingers, 2005); as such, an Indigenous research framework is a decolonizing one. Reclaiming of knowledge is part of this decolonizing framework. The rationale for a decolonizing Indigenous research framework is summed up by Smith (2002: 1):

The term, 'research' is inextricably linked to European imperialism and colonialism ... the word research is probably one of the dirtiest words in the Indigenous world's vocabulary ... it stirs up silence, it conjures up bad memories, it raises a smile that is knowing and distrustful. 
The damage from western, colonial research frameworks extends far beyond research and university settings. Research is an extension of the colonial system with its incumbent unremitting trauma. Research informs theory (Smith, 2002) and policy (Ten-Fingers, 2005), both of which oppressed and continue to oppress Indigenous peoples (Smith, 2002; Ten-Fingers, 2005). The development of theory through Indigenous worldviews by Indigenous researchers and the subsequent influence of policy by Indigenous people are essential. This concept forms the basis of the decision to include myself as a participant and as a researcher. Within the qualitative research literature, my role may be called "participant/observer" but within an Indigenous research framework, I would argue that this term is inadequate. Bastien (2005) discusses the importance of Indigenous researchers being involved in the research and developing or growing as a direct result of the research. 1 agree with Bastien, that our dual role as researcher and being part of the communities is extremely important. This dual role strengthens the research, much in the same way that community-based research claims that being part of the community being researched is an advantage (Minkler and Wallerstein, 2003). However, we need to recognize the impact we have on the research in this dual role. The power we carry as "researcher" tempered with our intimate relationship with the community is something we need to be aware of throughout the entire research process. Keeping a reflective journal and involving the community in all aspects of the research, including the development of the research approach or questions, methods, analysis, interpretation of the results, and how the research results are used can ensure our dual role does not bias the research. 1 kept a reflective journal and collaborated with the community, including the Elder throughout the entire project.

Decolonizing Indigenous research frameworks incorporate Indigenous theoretical knowledge. Brant-Castellano (2000) has characterized Indigenous knowledge as encompassing three processes: empirical observation, traditional teachings, and revelations. Empirical observation in this context is not based on quantitative inquiry in controlled settings. Rather, Indigenous empirical knowledge is a representation of "converging perspectives from different vantage points over time" (Brant-Castellano, 2000: 24). A result of this practice is traditional medicines. Indigenous people found out what plants had medicinal properties and this knowledge has been handed down through generations. This practice forms the second type of Indigenous knowledge: traditional teachings. Traditional teachings encompass knowledge passed down orally by knowledge keepers. Knowledge through revelations such as 
dreams, visions and intuition sometimes regarded as spiritual knowledge is a third type of knowledge. This type of knowledge is comprised of messages coming from the spirit world and our ancestors. Certainly, some Indigenous researchers acknowledge the guidance received from the spirit world (Bastien, 2005).

It is important to allow Indigenous knowledge to guide and shape the research framework. When we take traditional teachings and imbue them with theory from an Indigenous perspective, it becomes Indigenous theory and scholarship. In this research the medicine wheel teachings of health provide the Indigenous theoretical basis. The medicine wheel and its four quadrants, the physical, emotional, mental and spiritual, is where we began.

In describing an Aboriginal framework for practice in a Canadian social work context, Morrissette et al. (1993) state that core Aboriginal values and beliefs should be integrated. Morrissette et al. are referring to an Aboriginal framework for delivering services in Aboriginal communities. However, this concept can be used to explain an Indigenous research framework. Indigenous research frameworks incorporate the core values, beliefs and healing practices of the community throughout the research process.

In keeping with the cultural core values and beliefs integrated in an Indigenous research framework, a cultural consideration for this research project was the importance of "medicines" to the people involved in this project. Cree and Ojibwe teachings say plants and animals provide medicine for us. The four sacred plants - tobacco, sage, cedar, and sweet grass assist the community in connecting to the spirit world. Tobacco, sometimes placed in a cloth bundle, is given as a gift to an Elder when seeking advice or given to someone from whom knowledge or help is requested. This practice ensures things are done in a respectful way. This is sometimes referred to as being done in a "good" way. The person presented with the tobacco bundle can decline to accept the tobacco. A bundle carries responsibilities to do what is asked of you. If the recipient does not feel $s /$ he is able to carry out what is expected, the individual does not accept the tobacco.

Many Indigenous researchers include the use of the tobacco to demonstrate respect for knowledge the participant provides and to ensure the research is done in this "good" way (Baskin, 2006; Restoule, 2006). Whether research involves on-reserve or urban communities, all Indigenous people may not be aware of or want to acknowledge cultural ways, such as the tobacco bundle described above. Cultural genocide in Canada is a reality associated with colonization (Wesley-Esquimaux and Smolewski, 2004) and has been 
effective in assimilating many Aboriginal people. Many Aboriginal people do not understand the significance of certain cultural teachings and may not wish to take part in this if it is an aspect of a research study. Participants need to decide how they want to be involved in cultural ways included in the research. Some Aboriginal research participants may not view tobacco as a sacred gift and even after learning about the significance of tobacco may not wish to accept it, yet may want to be part of the project. Others may accept the tobacco out of respect for the cultural teachings but may not follow this belief. Either decision by the participants is acceptable.

Another cultural value that has been included by researchers (Baskin, 2006; Restoule, 2006) is smudging or a purification ceremony (Vern Harper, personal communication, April 2007). Smoke from sacred plants, such as sage and sweet grass are swept over a room, people, or objects. Before a ceremony or event, medicines are burned and offered to participants. Participants take the smoke in their hands and wash their head to clear their mind, their eyes so they can see good things, their ears so they will listen, their mouth so they will speak good words and their hearts so they will feel good things (Grafton Antone, personal communication, November 2001; Vern Harper, personal communication, February 2002).

Smudging and tobacco bundles are examples of integrating core values and belief into an Indigenous research framework. Researchers need to be prepared to teach or have an appropriate person teach the significance of cultural teachings included in research so the participants are able to make an informed decision. Researchers must recognize that in respecting differences amongst Indigenous peoples, there are similar considerations to an Indigenous research framework.

\section{INDIGENOUS METHODS}

Traditional values and beliefs were integrated into the methods used in this project, thus demonstrating how an Indigenous research framework and Indigenous methods come alive. Throughout this research gifts of tobacco were presented. A tobacco bundle was presented to the Elder of the program, the instructor of the program, the Executive Director of the NCCT, and the research participants. After explanation of the cultural significance of accepting a tobacco bundle, everyone offered a bundle accepted it, including the non-Aboriginal participants. The non-Aboriginal participants were aware and respectful of many of the cultural values and beliefs of Aboriginal people because of their involvement in the program and at the NCCT. 


\section{Sharing CiRCles}

The participants' experiences with the martial arts program were captured through the use of sharing circles. As a research method, sharing circles are similar to focus groups used in qualitative research where researchers gather information on a particular topic through group discussion. The use of sharing circles in Indigenous research has been described as circle methodology. This is a method that can be familiar and comforting for Indigenous research participants because the circle has a long tradition in Indigenous cultures (Restoule, 2006), as healing, learning, or sharing circles are used in some Indigenous cultures as part of ceremony and as a way of healing (Stevenson, 1999). In contemporary times, sharing circles are increasingly being used by Indigenous researchers (Baskin, 2006; Restoule, 2006). In a research setting, while both the focus group and sharing circle are concerned with gaining knowledge through discussion, the principles behind a sharing circle are quite different. Focus groups extract data while circles are acts of sharing with permission given to the facilitator to report on the discussions in the sharing circle (Nabigon et al., 1999). The sharing circle is spiritual and carries vast meaning far beyond the description that can be provided in this paper. However, Nabigon et al. (1999) acknowledged that energy is created in the circle by the spirit of the people involved and there is a recognition of the spirits of our ancestors and the Creator being present in the circle. The circle is non-judgmental, helpful, respectful and supportive. Sharing circles incorporate appropriate cultural teachings of the group involved.

As noted, the Aboriginal participants of this research came from a variety of Nations (Ojibwe, Cree, and Métis). Living in Toronto most of my life, my cultural teachings have been influenced by Ojibwe and Cree traditions. It was easy for me, as a researcher and facilitator of the sharing circles, to bring in appropriate cultural practices. However, 1 also asked the participants for their input on how the circles should be carried out. As stated earlier, the nonAboriginal participants were familiar and respectful of the cultural practices because they were incorporated into the martial arts program.

Researchers intending to use sharing circles cannot merely place people in a circle, share stories, and then use the term sharing circles. Researchers who are not familiar with the teachings and want to use sharing circles can involve an Indigenous person who carries this knowledge to guide the sharing circle. 
There were five sharing circles held to accommodate the participants' schedules. Each circle had 2-4 participants. The sharing circles were opened with a smudge. Participants were offered tobacco bundles after the project was explained. The sharing circles were guided by the medicine wheel teachings and focused on finding out participants' stories regarding their decision to participate in the physical activity program and what impact, if any, the program had on their lives. The questions asked included how the program had had an impact on their lives, physically, emotionally, spiritually, and mentally.

\section{Anishnabe Symbol-Based Reflection}

Symbols, the making of symbols, and art that displays symbols have significant cultural and spiritual meaning among many Aboriginal people. When Aboriginal artists make something, such as a painting, jewellery, a medicine wheel, or dream catcher, their energy is said to be placed into that object. The making of symbols and art is often very spiritual and unique for each person (Kim Wheatley, personal communication, September 2004). Symbols are often considered sacred because of this spiritual significance. For these reasons, using symbols in research is an ideal approach that truly reflects an Indigenous method.

Anishnaabe Symbol-Based Reflection was piloted in this project. The name of this method, Anishnaabe Symbol-Based Reflection was developed with the participants. The term, Anishnaabe is a term used primarily by Aboriginal people who identify as Ojibwe, Algonquin, Oji-Cree, and Odawa (Eigenbrod et al., 2003). The sharing circle and Anishnaabe Symbol-Based Reflection are further described in Lavallee (2007). This method comes as a gift from Anishnaabeg ancestry. Chi Miigwetch.

At the end of each sharing circle participants were asked if they wanted to participate in the second aspect of the project. Eleven of the seventeen elected to participate in the Anishnaabe Symbol Based Reflection. Five participants were male and six were female. Two identified as non-Aboriginal. Both non-Aboriginal participants identified as either artists or artistic. The eleven participants were asked to think about a symbol that captured the meaning of the martial arts program in their lives. They were instructed they could make the symbol themselves or the symbol could be purchased. Participants were given approximately 6 weeks to make or purchase their symbols. A maximum of $\$ 30$ was provided to the participants to cover the cost of the materials. 


\section{The StORIES AND SyMbOlS}

The sharing circles and symbols demonstrated that participants' involvement in the martial arts program had an impact on other aspects of their lives. Like the medicine wheel's teachings of balance between the four quadrants, the participants' stories affirmed that as they brought the physical dimension of their lives into a healthy balance, the other aspects of their lives were positively impacted.

\section{A Collective Story}

Storytelling has become an integral part of Indigenous research with individual stories contributing to a collective story (Smith, 2002). In this research, nine interconnected themes emerged from the individual stories and symbols. These nine themes told the collective story. The nine themes emerged from analysis of the sharing circles and the symbols. The analysis was done by the principal researcher and a community research assistant. The nine themes, as well as all the direct quotes used in all written materials, were brought back to the participants to confirm if they felt this reflected their stories. The participants agreed with the nine themes and the use of the direct quotes.

The nine themes were the following: 1) stories related to the past; 2) hopes for the future; 3 ) importance of the NCCT as a meeting place for urban Aboriginal people; 4) the importance of the physical activity program being offered through the NCCT; 5) stories related to physical impacts of the program; 6) the mental impacts; 7) the emotional impacts; 8) the spiritual impacts; and 9) stories of how they walked in life, taking everything they learned through their involvement in the program.

The participants' stories were rich in description and were far too lengthy to include in this paper. Therefore, this paper will focus on the four realms: the emotional, mental, spiritual and physical impacts and how they relate to the stories of their past and hopes for the future. In addition, the symbols relevant to these four realms will be highlighted. For more detailed stories please see Lavallée (2007).

In order to remain anonymous, participants choose pseudonyms rather than using their actual names. No specific information, such as age, nation or ethnicity is given in this paper as this could identify individuals. 


\section{The Historic Trauma of our Pasts}

\section{White Spider's Story}

1 wanted to take martial arts for me. You grow up with alcoholism and violence. For me, personally, you feel vulnerable. You grow up, you always have to look over your shoulder. You don't feel love or respect. You're constantly fighting. Why I wanted to do taekwondo was to feel empowered. If someone tried to hurt me I could hurt them. I think initially that is what it was for me.

\section{Hawk's Story}

1 had attempted suicide twice in my life by taking a lot of pills... I went to different western medicine things like psychologists, different programs but 1 had a bad experience with the doctor and didn't stay in any programs... I went to an Elder and told him about my situation. He sent me to [an Aboriginal agency] where I participated in sharing circles for the first time. After that program was done 1 checked out the Native Canadian Centre website to see if there were any programs for healing. I saw the taekwondo program and thought, 1 have to come to the taekwondo program.

Participants shared stories of their past journeys and how the martial arts program helped them address issues stemming from their pasts. Common stories were told by the Aboriginal participants: child, family, and relationship abuse, family dysfunction, foster care, violence, alcoholism, substance abuse, suicide attempts, isolation, low self-esteem and feeling undeserving, internal negative stereotypes of self and other Aboriginal people, single parenthood, sub-poverty, unstable living conditions, gang and criminal activity.

Several participants identified the relationship to the current "dysfunction" of Aboriginal people in Canada to intergenerational grief or historic trauma. This substantiates Wesley-Esquimaux and Smolewski's (2004: 53) statement that "Aboriginal people are beginning to understand that many of the social problems they deal with everyday have roots in the extensive historic trauma experienced." 


\section{Martial Arts Filling a Vold}

Kirmayer, Brass, and Tait $(2000: 6)$ state that forced assimilation and cultural genocide of Indigenous people left many people with "profound problems of identity and self-esteem." These problems are a "direct consequences of a history of dislocation and the disruption of traditional subsistence patterns" and have led to the physical and psychological ill-health of Indigenous people that is demonstrated throughout the world today. Historic trauma has created a void in Aboriginal people with respect to their cultural and racial identities and in turn has affected their ability to become healthy individuals. The instructor of the program said that what people sought or obtained, knowingly or unknowingly, from participation in martial arts helped to fill the different voids in each of their lives. He stated:

When you talk about the seniors program and the meals program, people have a clear and conscious understanding of that. And both those programs fill a void. The void is hunger. You have to get people to understand the void that taekwondo fills. The only way you can get people to understand that void is by talking or sharing stories and experiences of people in the group to understand what void has been filled. It's an individual thing.

The themes that emerged from the stories and symbols related to the emotional, mental, spiritual and physical benefits of the martial arts program related to "voids" in the individual lives of the participants. Although there were similarities in the stories of the participants, each person had a unique past that had an impact on them today. The martial arts program was an avenue for them to work through these challenges or voids.

The four realms will be discussed as they relate to the voids in the participants' lives and the subsequent benefits of their participation in the martial arts program. The emotional benefits were most detailed, followed by spiritual benefits. Although each of the realms will be discussed separately, there was interconnection between the four realms. For instance, at times a benefit of participating in the program was both emotional and spiritual or physical and mental. 


\section{Benefits to Emotional Well-Being}

Participants described emotional aspects that related to their healing and participation in this program. Many of the emotional themes were linked to their stories of identity, particularly being Aboriginal in an urban environment. Some described feelings of isolation that were alleviated through participating in martial arts. Sometimes this isolation was described as a result of moving to the big city, dislocation, and the adjustment of not being close to nature, or 'the bush'.

\section{Nimky-Nene}

I'm a small town boy, I like the bush. Being in the city, I don't have the energy that you get from being in the bush.

\section{Riel's Story}

Again, 1 kind of found myself being alone in this big concrete jungle here and not doing the things I like to do, like canoeing, snow shoeing and skiing cross country, you know... It [martial arts] just gave me that great feeling. 1 come in here and it's such a good feeling and when 1 leave here, it comes with me too. 1 feel great. It sort a leaves a lasting impression on you, you know. 1 know, ok, it starts to wear off and bang - I'm back here, two days later. 1 just feel great. You know.

The emotional benefits of the program filling this void of isolation was the development of a sense of family and community. White Spider's and Dove's stories and symbols reflected the theme of family and community.

\section{White Spider's Symbol and Story}

1 could feel the itch to take classes, but I would come up with excuses, you know? Like, "I'm tired." But 1 did it. I dragged my feet lots of times, but 1 still did it. 1 know that 1 need self-discipline and to exercise and socialize - to laugh, you know? 'Cause sometimes you get isolated. It's not just about the class. Just to see people. You know what I mean? It's social but it's also self-discipline. 
White Spider's symbol was a collage of pictures that included a picture of herself as a child, her brother, mother, Nanan (grandmother) and Mushoom (grandfather). She described this picture as her "Cree Family" and placed phrases over the picture describing her relationship to each of these people and their impact on her life. White Spider finishes her description of the portrait with, "And I am alone in Toronto, one of the biggest cities in Canada." Turning over the picture exposed a more recent photograph of her and her sons competing at the Ontario Aboriginal Sport Circle Games in 2005. She called this side "Taekwondo - we are a community." She wrote the following:

Toronto can be a hard place to survive and can also be a lonely place. Going to the Native Canadian Centre taekwondo program creates a sense of being home. We laugh out loud, we tease, and work together. In taekwondo class I have selfdiscipline, support and people who will back me up. My children and 1 are a small family and it feels good to be able to do something together as a unit. Together we can beat the odds.

Dove's symbol reflected filling the void of isolation with a sense of family and community fostered by the martial arts program. Her symbol was titled "Taekwondo is one big family." Her symbol was a collage of pictures placed in a circle that represented Mother Earth. These pictures

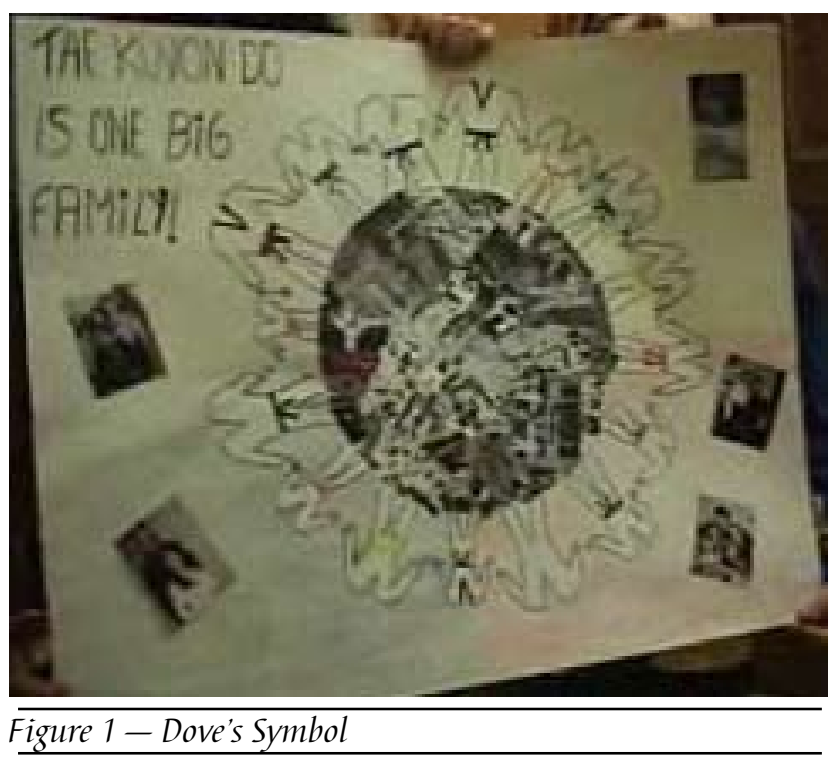
were of the martial arts participants taken over several years. Surrounding these pictures she drew martial art uniforms with different coloured belts holding hands. This 
symbolized the participants of the program coming from different parts of the world, but joining hands as one family. On the outside of this circle she placed several pictures of herself, her partner, and her two sons who are part of the program.

For some participants, the issue of identity was linked to reconnecting to blood relatives. Riel and Dumont are brothers who did not know each other as children and young adults. Riel is older than Dumont and left home when Dumont was young. It was a coincidence that they obtained jobs with the same employer in Toronto but never ran in to one another at work. Someone at their work place who knew both of them inquired if they knew each other because they had the same last name. They were surprised to find out that they both worked for the same company but never got to see each other. On separate occasions, they met the same person, an Aboriginal man, who participated in the martial arts program at the NCCT. He encouraged each of them to participate. It was through martial arts that they strengthened their relationship as brothers.

\section{SPIRITUAL GROWTH}

The participants spoke of the importance of the martial arts program being offered in an Aboriginal cultural centre and taught by an Aboriginal instructor. The physical activity program served as an avenue that led some participants to furthering their understanding of culture and identity as an Aboriginal person, which contributing to their spiritual growth. This was expressed directly in the martial arts program with the instruction of the martial arts incorporating traditional teachings, but also related to participants learning about other cultural programs and ceremonies offered at the NCCT.

\section{Eagle's Story}

Because the program is held within in the Aboriginal community, in an Aboriginal environment, led by an Aboriginal instructor, that Indigenous component - a fine line runs right through all those things. Whereas a taekwondo school or specific school will only talk about the practice, techniques, some of the history and the application of it, but won't necessarily talk about culture, history and a lot of those things that directly reflect us, us as red bloods. 
During the martial arts class, there are other programs occurring throughout the NCCT, such as drumming and singing circles. The following was a discussion between Dumont, Riel, and Redman about the drums that are often heard during the class and have sometimes been part of the martial arts class during times of testing.

Dumont: Drums - oh boy!

Riel: Dumont and 1 hear those drums going and - oh! It's going to be a good work out tonight. It feels good.

Dumont: It's so powerful. 1 remember [going to drumming before class] and, oh the drums! In this small room and the effect it had on me that evening. It was just so powerful.

Redman: When we did the blue belt test, the way we opened for testing and the way we closed for testing. I was really proud that we started incorporating more of Native culture into the taekwondo program.

Dumont: That's the key point too with taekwondo, practising it here is not like practising it anywhere elsewhere... This doesn't only touch base on taekwondo, but it educates us as far as our own heritage with the aboriginal theme as well. [Our instructor] has done a great job with incorporating the two so. So that's been a real bonus.

Dumont stated that the martial arts program at the NCCT could not compare to other programs because of how the instructor educated participants about their own Aboriginal heritage. Other participants shared similar stories.

\section{Nimky-Nene's Story}

1 like the fact that [our instructor] incorporates the Medicine Wheel teaching and Grandfather Teachings and different teachings of culture. It's very interesting seeing a man of his stature, so kind about it, not cocky about it. That's what made me walk through these doors. It was scary, but people were welcoming, came and said hello. 
Rather than the spiritual experience coming from other programs offered at the NCCT or through traditional teachings done in the martial arts class, some of the stories spoke of the interconnection between physical activity and spiritual growth. Some of the stories and symbols related to spiritual growth were tied to cultural identity. For instance, Hawk wrote about challenges with identity and a sense of undeservingness. She described two symbols that embodied the emotional and spiritual strength she gained through martial arts. While her story is discussed here under spiritual growth, her story is equally tied to emotional healing.

1 know that not all Native people are searching for their identity, but my life has been a life long journey of trying to understand who and what $1 \mathrm{am}$. This has caused problems for me. 1 understand now that the biggest problem was the sense of undeservingness 1 have. 1 don't think of it as a lack of self-esteem. Coming here is opening my eyes that $1 \mathrm{am}$ deserving. 1 am deserving of my black belt, 1 am deserving of having people care about me and not hurt me. My medicine wheel with the hawk - my clan - symbolizes my healing journey and the growing understanding 1 have of myself as

\section{Anishnaabe.}

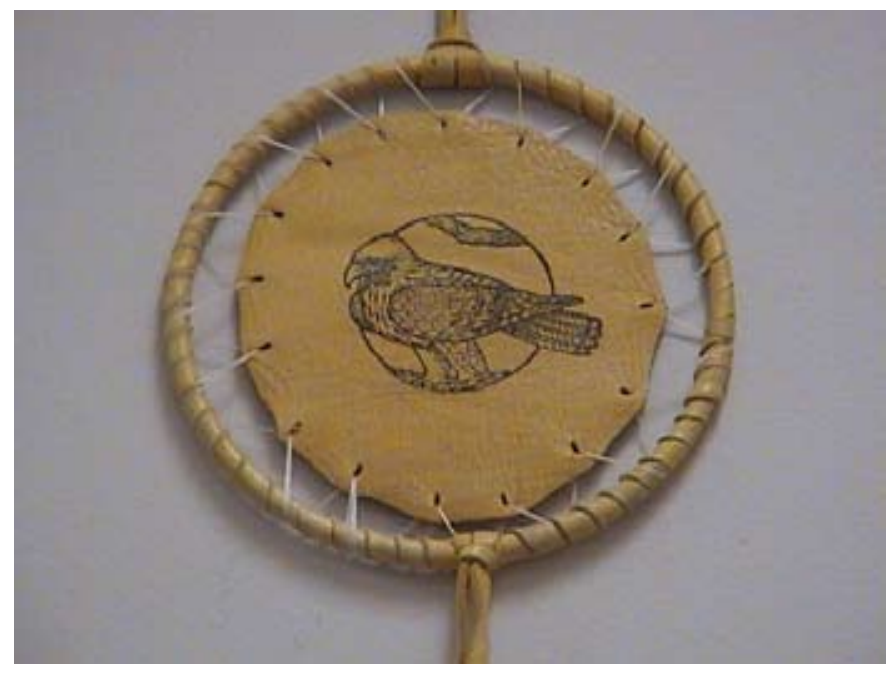

Figure 2-Hawk's medicine wheel 
Hawk's second symbol was a song that she had learned while attending one of the women's drumming circles. She saw the martial arts program as the avenue that brought her to other cultural events.

Kwe - As a woman. My undeservingness as a woman - l'm understanding through our informal healing circles in the bathroom and the strength that 1 get when I walk through these doors that my undeservingness is a symptom that comes from our long history and how we unlearned our ways to respect women. It comes from my Dad and his Dad and so on .... and in turn the men 1 have selected because I'm comfortable with and expect to be treated unwell. So, my next symbol is The Strong Women's Song. The song that 1 know has brought me helpers to unlearn this lack of deserving.

Hawk expressed the "profound issues with identity" and deservingness that are demonstrated in many Aboriginal people (Kirmayer and Brass, 2000). Her involvement in the martial art program was a forum to work through her sense of deservingness and her cultural identity, transferring the skills learned in martial arts to other life experiences. This transferability of life skills through sport has been recognized in the field of sport psychology (Danish and Nellen, 1997; Petitpas et al., 2004).

Nimky-Nene's story and symbol depicted the interconnectedness of physical activity and spiritual growth. Unlike some of the other participants who only began to participate in cultural ceremonies and events through their involvement in martial arts, Nimky-Nene was already involved in ceremony, drumming, singing and dancing. He understood many of his traditional teachings. However, he still expressed a void after moving to the city.

As a younger man, as a kid, I was always active and I was doing stuff physically: riding bike, hockey, baseball, and so on. Once high school was done and 1 started college and moved to the city all those things stopped. A series of events happened and my spirit - the light, wasn't shining as bright ... what 1 call a dying spirit, a fading spirit... I felt I was getting sicker and sicker the longer I stayed here [in the city], but 1 
had responsibilities and I needed to stay here so I looked at my past and tried to figure out how I could bring back my spirit. I figure out, 'cause I went to circles and ceremonies and talked to people and tried different things but I didn't try physical exercise... I needed to get physically active.

He further described how he visualized his spirit (as pictured in his symbol).

The only thing 1 can picture or imagine is how my spirit is in my belly, my energy in my belly. Before I could not feel it unless I was in ceremony, deep in ceremony and now everywhere I walk 1 can feel it, I can feel it and other people can see it. It's that attraction - kids come to me. I can physically chase them around now [laughing]!

Nimky-Nene made a beautiful large soap stone carving of a man who resembled him wearing a martial arts uniform. He had a long braid and in his hands held around the level of his waist was a ball that symbolized his spirit. The ball was not available at the time of this picture. It was to be a blue marble ball.
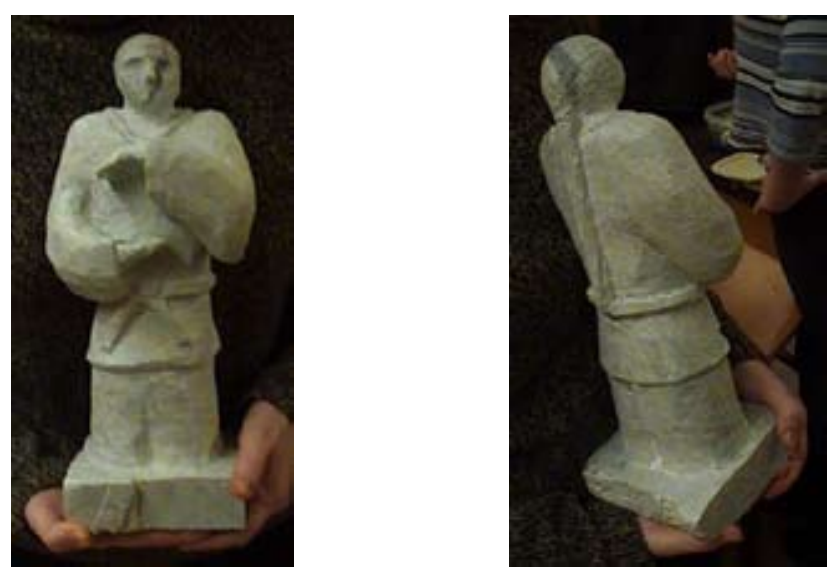

Figure 3-Nimky-Nene's soap stone carving

The void that physical activity filled for Nimky-Nene was spiritual and he articulated this in his story and through his symbol. Turtle also made specific 
reference to the taekwondo program filling the void of spiritual hunger and called the martial art program "spirit food." She made an elaborate symbol consisting of a medicine shield, dream catcher, and medicine wheel to describe her involvement in the martial arts program. While she stating the program was spiritually uplifting, she also spoke of emotional development. She did not separate the two. She shared that though participation in the program itself was seemingly a small action, it gave her eternal gifts of knowledge, healing, self-preservation, respect, dedication, and opportunities on which she would have otherwise missed out.

\section{Benefits to Mental Well-Being}

There were fewer stories relating to the mental benefits. However, some of the mental benefits overlapped with the emotional benefits. At times it was difficult to separate the mental benefits from emotional because they were discussed together, as noted in Redman's story.

\section{Redman's Story}

In my family relationships, it's made me more patient.... It's opened up

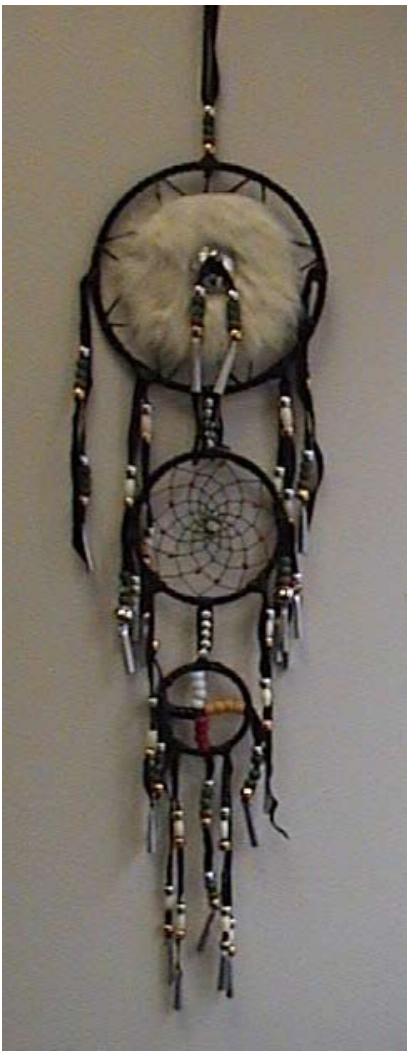

Figure 4 - Turtle's medicine shield, dream catcher and medicine wheel my head. It's made me more mature, recognize my short-comings, recognize my strong points. It's made me more of a man and more mature. 1 feel better about myself about the last four years than my life before martial arts.

The mental benefits also included stress relief from work and other life events and clearing the mind as noted by Crane.

\section{Crane's Story}

Physical exercise for me, helps put me in a better mood and a better frame of mind and basically unclouds my thinking. 
So, just a better mind set or head space when working out regularly.

\section{Benefits to Physical Well-Being}

The sharing circles usually started with very brief stories about the physical benefits. Several participants stated they began the program to get fit and lose weight but realized other non-physical benefits after staying with the program. Once again, relative to the stories about the benefits to emotional and spiritual well-being, there were fewer stories related to the physical. However, everyone reported some type of physical benefit. Participants described the importance and love of physical movement, improved physical health including losing weight and preventing diabetes, and the ability to defend one self physically if they had to. Perhaps these stories were brief because of the more obvious understanding of the benefits of physical activity. However, it is important that the physical benefits for Aboriginal people in particular be highlighted, as noted by Crane. He described why Aboriginal people need physical programs:

Native people need programs, especially because of poor health and the program could lead to healthier living, nutrition, as well as healthier lifestyle, discipline as well. It's also a good way to relieve stress and control energy.

\section{INTERCONNECTION AND BALANCE}

Although this paper has categorized the stories into emotional, mental, spiritual and physical benefits of physical activity, the stories also reflect the interconnectedness and balance of the four realms. Bimadiziwin's name, symbol and story reflect this interconnectedness and balance. In her Ojibwe language, Bimadiziwin means "good life" or a "good way of life" or "a healthy way of life." She made a medicine wheel keychain as her symbol and focused on the Seven Grandfather ${ }^{2}$ teachings in her story. She explained how this teaching intertwined with martial arts assisting her in striving for balance. She wrote about the Seven Grandfathers: Honesty, Humility, Respect,

2 The Seven Grandfathers outlined are based on the participant's teaching. Some teachings include truth in place of kindness. Kindness is one of the Thirteen Grandparents. The Thirteen Grandparents incorporates the female aspect (Lee Maracle, personal communication January 2007). 
Courage, Wisdom, Love and Kindness, and gave a personal story of how each has been experienced through the program. Here is part of her story:

Love - I feel there is an aura of love in our Do Jang,, the love for the freedom of physical movement, the love for the sense of community, for the friendships and from its members who unselfishly give of their kindness to one another.

Courage - Being involved with taekwondo has further enhanced my abilities and given me more courage to continually challenge myself in all aspects of my life so that 1 may continue to strive for growth and change.

As for my symbol, I have created a Medicine Wheel keychain to remind me of my ultimate goal in how 1 need to live my life and how taekwondo and the Seven Grandfathers lay a path for me to get there. Nahow.

Bimadiziwin's name, her medicine wheel and the medicine wheels created by Hawk and Turtle reflect their healing journeys. Their involvement in the martial arts program was an important part of their healing journeys, awakening the healthy balance of physical, mental, emotional and spiritual well-being.

\section{Concluding Thoughts}

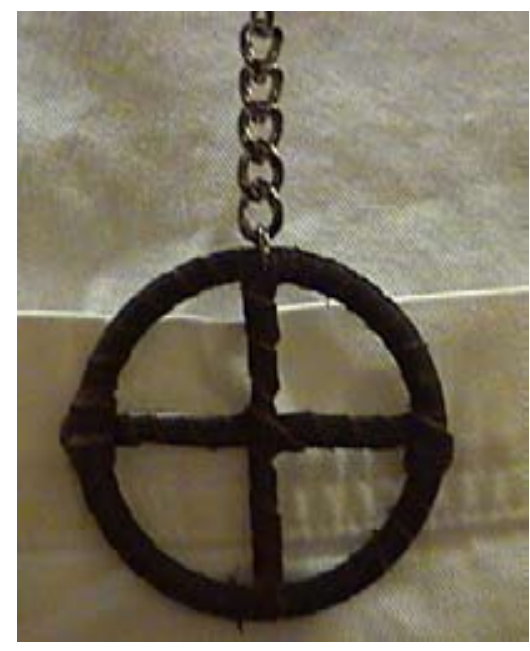

Figure 5 - Bimadiziwin's medicine wheel key-chain

Wilson (2001) discussed axiology or morals of an Indigenous research methodology, specifically that Indigenous researchers are accountable to all their relations, including the participants of the research. Research must do something beneficial in this world. The recommendations for research and policy that have come out of this research reveal this accountability. 
Rather than using Western theory and methods, this research acknowledges all my relations with the focus on an Indigenous way of knowing. The rationale for this research was an Indigenous concept of health based on seeking balance of emotional, physical, mental and spiritual well-being. This medicine wheel teaching of health provides a different way to promote physical activity programs. Rather than focusing on just the physical or physiological impacts, the medicine wheel teaches us to take a holistic view, acknowledging the balance of the physical with mental, emotional and spiritual well-being. This Indigenous approach to exploring the impact of physical activity is a future recommendation for research, as well as for agencies delivering such programs. Rather than focusing on specific variables or making blanket statements about the psychological, physical or social impacts of physical activity, this research suggests that each person gains different things from their involvement. Each person has a different "void" that is filled. In addition, the benefits that participants spoke about did not fit into only one category, but there was a connection between how physical activity impacted emotional, spiritual, mental and physical well-being in an integrated way. It is recommended that future programs and research acknowledge this interconnection, as well as the differences between individuals.

The participants of this research expressed ways in which this research had a positive impact. One of the unexpected outcomes of the Anishnaabe Symbol-Based Reflection was the therapeutic effect the participants described as a result of making their symbols. As noted earlier, the making of symbols can be a spiritual experience for some Indigenous people. Some of the participants in this project expressed the spiritual significance of making their symbols, particularly the medicine wheels. For instance, Bimadiziwin stated that she "needed" to make a medicine wheel and this project pushed her to do so. The therapeutic impact of this method was separate from the benefits from the martial art itself. Participants also expressed appreciation for being given the opportunity to share their experience in sharing circles because they had not had this opportunity. Finally, this research provided the NCCT and the instructor of the program with research evidence of the program's success that can be drawn upon when trying to obtain funding. In fact, the results of this research have already been used in a funding proposal by the instructor of the program.

The generalization of these findings or how well these results may translate to other communities needs to be considered. It is recognized that in order for people to participate in such a physical activity program they must 
have a certain level of physical health. In addition, this research involved urban Aboriginal people and may not be directly translatable to Aboriginal communities on-reserve or other Indigenous communities. For instance, the importance of the NCCT, a meeting place for urban Aboriginal people may not be as important on-reserve. However, the martial arts program acting as an avenue for the introduction of other cultural teachings may still be applicable. One must not assume that people living on-reserve have not experienced the same acculturation as urban Aboriginal people.

The participants in this research recognized the importance of the physical activity program being offered in an Aboriginal centre where other cultural programs and ceremonies were offered. Even non-Aboriginal participants enjoyed this aspect of the program. It was not just the physical activity program, but the fact that it was offered in a particular setting. The NCCT was a comfortable and safe place. A future policy recommendation is to offer physical activity programs for urban Aboriginal people in an Aboriginal cultural centre.

In the City of Toronto, which is where this project took place, while there are several Aboriginal organizations, there is not an Aboriginal recreation centre or an agency with a specific mandate of delivering recreation programs to the Aboriginal community. The NCCT is located near a religious-based community recreation centre, which is a state-of-the-art facility that offers cultural and recreation programming. White Spider asked, "Why is it that Aboriginal people cannot have something similar?" While the participants were grateful for the martial arts program, they recognized the need for a more adequate space with a proper gymnasium, equipment and showers. The martial arts program is currently run in the auditorium of the NCCT and competes for space amongst the other programs. A further policy recommendation is that urban communities develop Aboriginal cultural recreation centres where cultural activities can take place in the same space as physical recreation.

The instructor of the martial art program was Aboriginal and incorporated traditional teachings in his instruction. Other physical activity programs, not just martial arts, may achieve similar impacts demonstrated in this program if the program integrates traditional ways. For instance, an Elder is part of this martial arts program and participates in various events, including the testing for belts. In addition, smudging, drumming and singing have been part of testing. Physical activity programs can achieve similar results by 
involving Aboriginal people in the delivery of the programs and bringing in cultural values and practices. Participants of the programs can be involved in thinking of ways to immerse Indigenous culture in the delivery of physical activity programs.

This research demonstrated that physical activity not only benefits people physically, but it is also integrally interconnected to emotional, mental and spiritual well-being. The stories told of filling of emotional, mental, physical and spiritual voids created by unremitting historic trauma. While the participants' stories told of unremitting historic trauma, in the same breath they spoke of hope for the future. They spoke of their healing journeys, mentally, emotionally, physically and spiritually. Their stories recognized their colonial pasts, not as victims but as strong Aboriginal people. Recognizing our colonial pasts takes us one step further along our healing journey, not to blame others or play the role of victim, but to recognize the impact of history on our people. Programs, such as the one described herein, can empower individuals and instill a sense of "Native pride" to be able to acknowledge the past yet set their sights on a hopeful and healthy future.

\section{REFERENCES}

Anishnawbe Health Clinic

2006 Anishnawbe Health Brochure. Toronto: Anishnawbe Health.

Archibald, L.

2006 Decolonization and Healing: Indigenous Experiences in the United States, New Zealand, Australia and Greenland. Ottawa: Aboriginal Healing Foundation.

Baskin, $C$.

2006 "Circles of Inclusion: Aboriginal Worldviews in Social Work Education." Doctoral Dissertation, University of Toronto, Toronto.

Bastien, B.

2005 Blackfoot Ways of Knowing: The Worldview of the Siksikaitsitapi. Calgary: University of Calgary Press.

Brant-Castellano, $M$.

2000 "Updating Aboriginal Traditions of Knowledge." In G. Dei, B. Hall, and A. GoldinRosenberg, eds., Indigenous Knowledges in Global Contexts. Toronto: University of Toronto Press.

Canadian Parks and Recreation Association.

1994 "Impact and Benefits of Physical Activity and Recreation on Canadian Youth-atRisk." Ottawa: Canadian Parks and Recreation Association. 
Chansonneuve, D.

2005 "Reclaiming Connections: Understanding Residential School Trauma Among Aboriginal People." Ottawa: Aboriginal Healing Foundation.

Coakley, J.

2002 "Using sports to control deviance and violence among youths: Let's be critical and cautious." In M. Gatz, M. A. Messner and S. J. Ball-Rokeach, eds., Paradoxes of Youth and Sport. Albany, NY: SUNY Press.

Danish, S.J. and V.C. Nellen

1997 "New roles for sport psychologists: Teaching life skills through sport to at-risk youth." Quest 49: 100-113.

Eigenbrod, R., G. Kakegamic, and J. Fiddler

2003 “Aboriginal Literatures in Canada: A Teacher's Resource Guide (Resource Guide)." Ottawa: Curriculum Services Canada.

Halas, $\mathbf{3}$.

2001 "Playtime at the treatment centre: How physical activity helps troubled youth." Avante 7(1): 1-13.

Hartmann, D.

2003 "Theorizing sport as social intervention: A view from the grassroots." Quest (55): 118-140.

Kirmayer, L., G. Brass, and C. Tait

2000 "The mental health of Aboriginal peoples: Transformations of Identity and Community." Canadian Journal of Psychiatry, 45: 607-616.

Lavallee, $\mathrm{L}$.

2007 "Threads of Connection: Stories of participants involved in an urban Aboriginal cultural recreation programme." Doctoral Thesis, University of Toronto, Toronto.

Minkler. M. and N. Wallerstein

2003 Community-Based Participatory Research for Health. San Francisco: Jossey-Bass.

Morris, L., J. Sallybanks, K. Willis, and T. Makkai

2003 "Sport, Physical Activity and Antisocial Behaviour in Youth." Trends and Issues in Crime and Criminal Justice, Australian Institute of Criminology. Retrieved May 3 , 2007 from www.aic.gov.au

Morrisette, V., B. McKenzie, and L. Morrisette

1993 "Toward an Aboriginal Model of Social Work Practice." Canadian Social Work Review 10(1): 91-107. 
Nabigon, H., R. Hagey, S. Webster, and R. Mackay

1999 "The learning circle as a research method: The trickster and windigo in research." Native Social Work Journal 2(1): 113-137.

National Aboriginal Health Organization

2005 “First Nations Regional Longitudinal Health Survey (RHS) 2002/03: The Peoples' Report." Ottawa: National Aboriginal Health Organization.

Native Canadian Centre of Toronto (NCCT)

2006 "Native Canadian Centre Martial Arts." Retrieved July 20, 2006 from www.ncct. on.ca/martialartsprogram.html

Petitpas, A.J., J.L. Van Raalte, A.E. Cornelius and J. Presbrey

2004 "A life skills development program for high school student-athletes." The Journal of Primary Prevention 24(3): 325-334.

Restoule, J.P.

2006 "Male aboriginal identity formation in urban areas: A focus on process and context." University of Toronto, Toronto.

Smith, L.T.

2002 Decolonizing Methodologies: Research and Indigenous Peoples. Dunedin: University of Otago Press.

Stevenson, $\mathrm{J}$.

1999 "The Circle of Healing." Native Social Work Journal 2: 8-21.

Ten-Fingers, K.

2005 "Rejecting, Revitalizing and Reclaiming." Canadian Journal of Public Health 96(1): s60-s63.

Wesley-Esquimaux, C., and M. Smolewski

2004 "Historic Trauma and Aboriginal Healing." Ottawa: Aboriginal Healing Foundation.

Wheatley, $\mathrm{K}$.

2004 Personal Communication, August.

Wilson, $S$.

2001 "What is an Indigenous research methodology?" Canadian Journal of Native Education 25: 175-179.

World Health Organization

2001 "International Decade of the World's Indigenous People: Report by the Secretariat." World Health Organization. 
